\title{
INTRA- AND INTER-FAMILIAL BEHAVIOUR OF GLAUCOMYS VOLANS (RODENTIA) FOLLOWING PARTURITION
}

\author{
BY ILLAR MUUL* \\ Museum of Zoology, University of Michigan, Ann Arbor, Michigan, U.S.A.
}

The remarkably strong propensity in female flying squirrels (Glaucomys volans) for retrieving their young has been noted by several naturalists. In one instance (Stack 1925) a female climbed up the pant-leg of an observer who had removed the young from a nest; she took four babies from the observer's hand and carried each of them to another tree cavity. During my own field work I have often observed female $G$. volans behave in this way; they have removed young even from my pocket. The retrieving behaviour is so strong that I began to rely on it in capturing lactating females, which attempted to retrieve the young placed in a trap, bag, or even a sock.

The females seem to be attracted primarily by the sounds emitted by the young. The sounds apparently need not be very precise. Even approximate imitations of them by this observer induced females to search around in the observer's clothing and around the face. The sounds sometimes appear to be ultrasonic, i.e. the babies can be seen going through the motions of making the sound and the female responds, but nothing can be heard by the human observer. In this regard the young appear to be similar to those of other rodents (Zippelius \& Schleidt 1956; Hart \& King 1966). Odour and visual stimuli also seem to be important.

In retrieving, the female flying squirrels behave much like females of other rodents (Beach \& Jaynes 1956; Eibl-Eibesfeldt 1963; Richards 1968). The baby is grasped by the leg, head, or the nearest extremity; the female turns the baby around in her fore-feet and grasps it firmly by the thigh, shoulder, or membrane (Plate I, Fig. 1). As the young mature, they are usually grasped by the membrane while their legs encircle the female's head. Similarly to Sciurus vulgaris (Eibl-Eibesfeldt 1963), flying squirrels handle nesting material and nuts much like they handle their young (Plate II, Fig. 2).

During experiments, in spite of the fact that the young were handled extensively, the females

\footnotetext{
-Present address: Department of Ecology, U.S.A. Medical Research Unit, Institute for Medical Research, Kuala Lumpur, Malaysia.
}

never destroyed their own babies. Thus, unlike hamsters and other small mammals, flying squirrels are well suited for experiments involving manipulation of young.

In captivity, lactating females retrieved young of others and in some instances also young mice (Peromyscus leucopus) and ground squirrels (Citellus tridecemlineatus). In retrieving, the females apparently received no negative feedback from the presence of their young or those of others in the nests. After retrieving all of their young they always returned to the spot where the babies were presented as if searching for more. Indeed, in a single sequence a female retrieved thirty-five young including her own litter and litters of other females. Another female was repeatedly presented with young from her own litter which were removed from the nest box. After retrieving the young fifty times without a pause, the female was hyperventilating and the experiment was stopped; there was no indication, however, that she would not have continued retrieving.

When young of various ages (but less than $\mathbf{4 0}$ days) were presented in a group, the females retrieved the youngest individuals at a greater frequency than the older ones, regardless of whether they were intra- or extra-familial. Although females often continued to nurse until about 60 days post partum, prior to 40 days post-partum, extra-familial young of about 40 days or older (and adults) were attacked if they were in the vicinity of the nest. Extrafamilial young of any age were attacked by females after about 40 days post partum.

Some females had litters in late summer and the post partum care period overlapped the annual period of intensive food storing (Muul 1968). During these times after a few young were retrieved, the females could be induced to retrieve hickory nuts, which they placed in their nests.

Numerous observations of this type led me to keep more precise records and to set up some controlled experiments to analyse further the retrieving behaviour of female flying squirrels. 
MUUL: POST-PARTURITION INTRA- \& INTER-FAMILIAL BEHAVIOUR OF FLYING SQUIRRELS

\section{PLATE I}

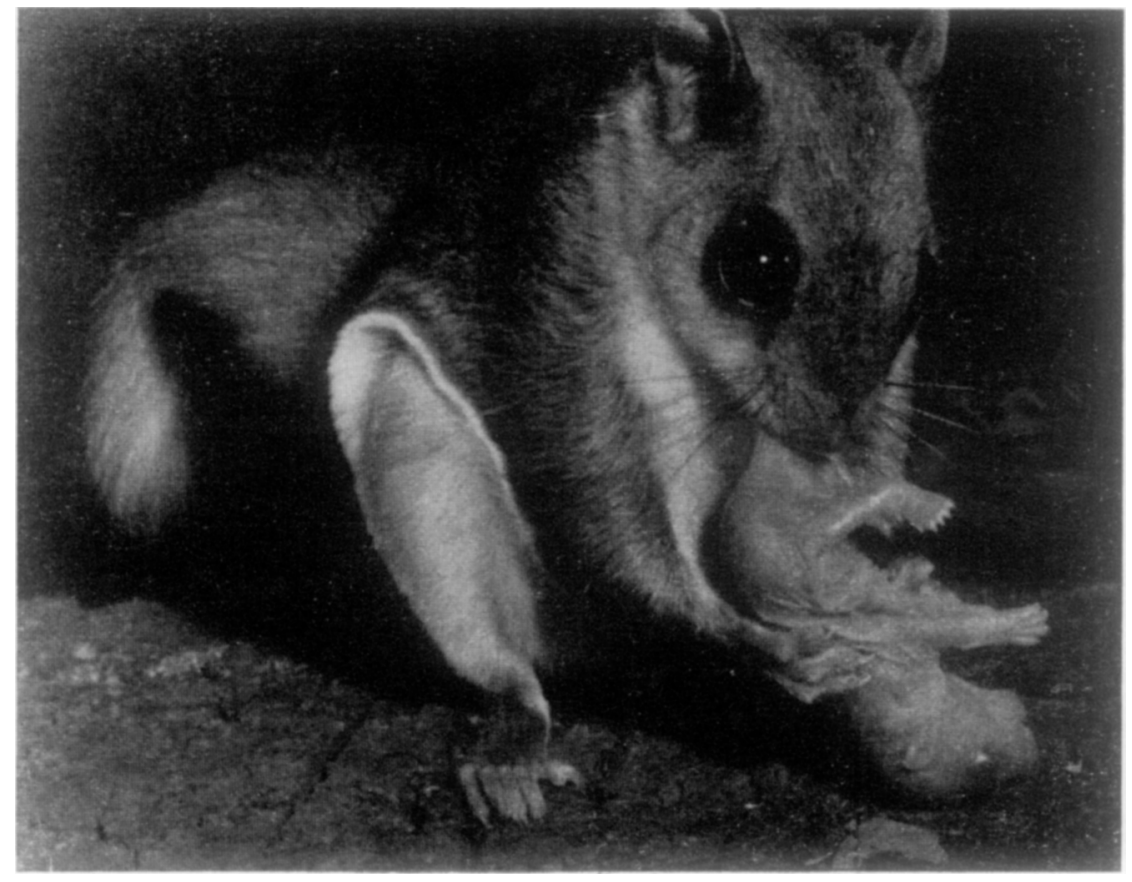

Fig. 1 
A N IMAL BEHAVIOUR, 18,1

PLATE II

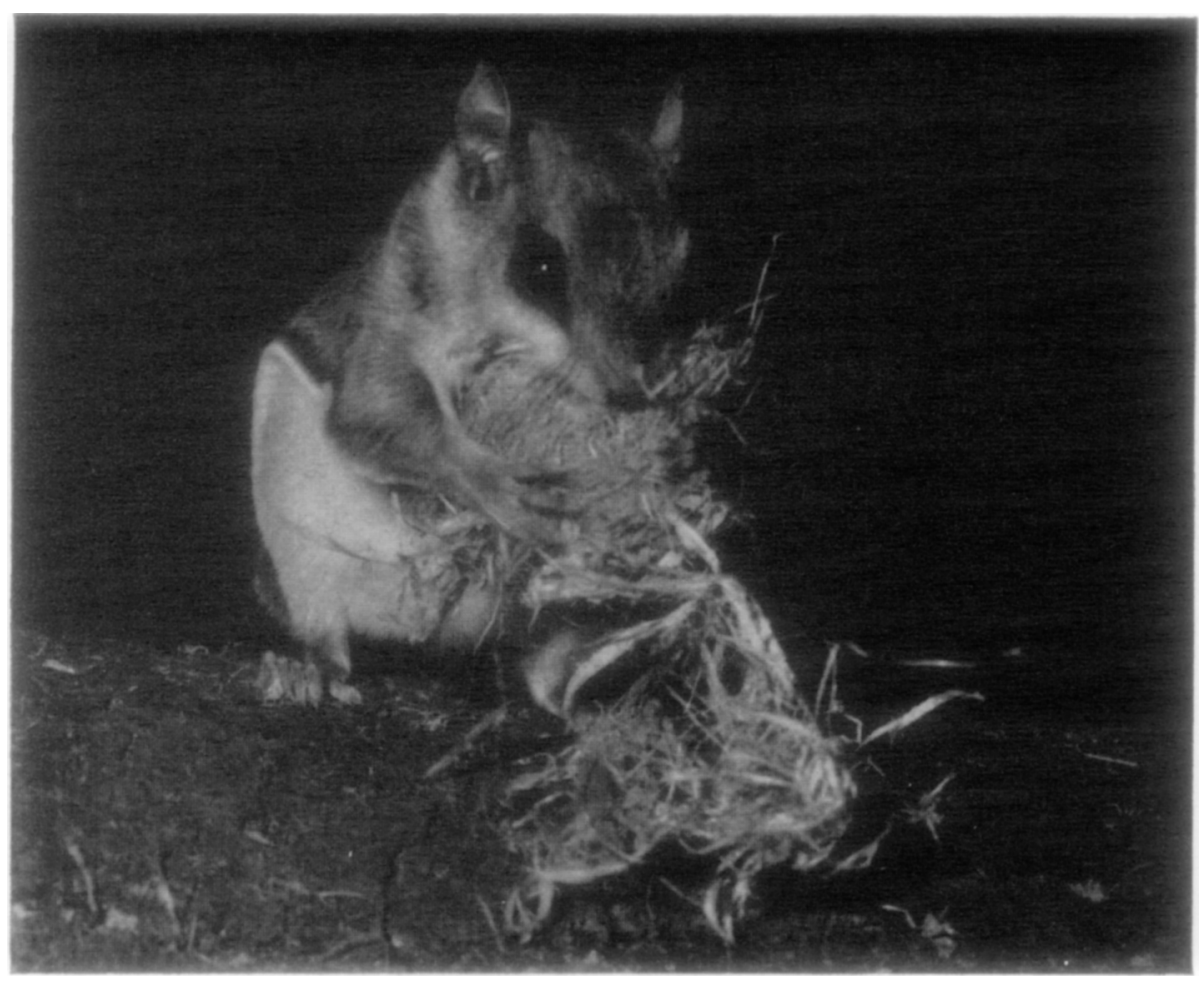

Fig 2 
The approach was to determine in various ways the duration of the post partum retrieving response, the response to extra-familial young through time, and the response to nuts during the post-partum care period. Table I summarizes the sequence of development of young $G$. volans and this will be referred to in the discussion of the response of the females toward young.

Table 1. Post-partum Ontogeny of Glaucomys volans*

\begin{tabular}{|c|c|c|c|}
\hline Age (days) & Physical appearance & $\begin{array}{l}\text { yuence } \\
\text { Motor }\end{array}$ & Sensory \\
\hline 1 & pink, hairless & squirming & $\begin{array}{l}\text { eyes closed, ears sealed, } \\
\text { pinnae flat }\end{array}$ \\
\hline 2 & & & ears sealed, pinnae erect \\
\hline 3 & $\begin{array}{l}\text { head greyish (melanin), anterior digits separating, } \\
\text { nape greyish }\end{array}$ & crawling & \\
\hline 4 & nape greyish & right itself & \\
\hline 5 & & clinging & \\
\hline 6 & fuzz on nose, chin & & \\
\hline 7 & back greyish & & \\
\hline 8 & anterior digits 2 and 5 separate & & \\
\hline 9 & fuzz on head & & \\
\hline 10 & $\begin{array}{l}\text { anterior digits } 3 \text { and } 4 \text { separate, fuzz on nape, } \\
\text { hair on chin }\end{array}$ & & \\
\hline 13 & posterior digits separate & & \\
\hline 15 & $\begin{array}{l}\text { fuzz on entire dorsum, hair on nape, } \\
\text { lower incisors erupting }\end{array}$ & & \\
\hline 16 & fuzz on pectoral region, fine hair on tail & & \\
\hline 19 & $\begin{array}{l}\text { head and dorsum brown, } \\
\text { hair on pectoral and abdominal regions }\end{array}$ & & \\
\hline 20 & & & ears open \\
\hline 21 & & climbing & \\
\hline 22 & tail distichous & & \\
\hline 23 & some hair on ventral side of patagia & defensive refiex & \\
\hline 25 & & lift head & \\
\hline 26 & & fast climbing & eyes open \\
\hline 28 & inguinal region furred & lift body & \\
\hline 29 & upper incisors erupting & & \\
\hline 37 & & $\begin{array}{l}\text { chew on nut shells } \\
\text { coming out of nest }\end{array}$ & \\
\hline 38 & & running & \\
\hline 41 & & $\begin{array}{l}\text { improved co-ordination } \\
\text { short glides }\end{array}$ & \\
\hline
\end{tabular}


ANIMAL BEHAVIOUR, 18,1

\section{Methods}

Altogether ten female $G$. volans, along with their litters, were tested; litter sizes varied from two to five and included various ages. The females were all wild-caught and were housed in $60 \mathrm{~cm}^{3}$ all-wire cages which contained a wooden nestbox with either a removable top or side door. All of the females were tested approximately the same number of times during their postpartum case period.

During the experiments young were removed from the nest-box and were presented to the female either on the cage floor or on a board outside the cage that the female could reach by leaving the cage. Young were presented in pairs: one intra-familial and the other extrafamilial. In successive presentations the intraand extra-familial babies were alternated from left to right in respect to the line of approach used by the female. The age differences of the babies were 2 to 9 days (mostly 6) or 18 to 19 days.

\section{Results}

Altogether 429 trials were run in which the age differences between the presented young were 2 to 9 days. These were not all independent observations, however, since a given female was tested several times during the time of her postpartum care period. In 266 of the trials the extrafamilial baby was older, in 163 it was younger. The females showed no preference for their own young: in 217 trials the females took their own baby; in 212 trials the extra-familial baby was taken. In 202 of these trials the animal that was taken was younger and in 227 trials it was older than the one with which it was presented.

A total of 222 trials were run in which the ages of the presented babies were 18 to 19 days apart. In 101 trials the extra-familial baby was older, in 121 trials it was younger. Again, the females showed no preference for their own young (103 taken) over those of others (119 taken). Irrespective of ownership the younger baby was taken more frequently than the older (196:26).

In experiments with ten females which had litters exceeding 39 days, twice the extra-familial young were accepted, but not retrieved (age of own litters 39 and 41 days), while the remaining eight females attacked the extra-familial young regardless of their ages (10 to 38 days). All of the females with litters less than 39 to 40 days old attacked extra-familial individuals older than $\mathbf{4 0}$ days.

\section{Additional Observations}

Exchange of litters. Litters ( 9 days age difference) of two females were exchanged before either litter was 40 days old. Independent of the ages of the 'adopted' litters in their charge, the 'transition' period from accepting to rejecting extra-familial young occurred at about 40 days post partum in both females, or when their own litters were about 40 days old. The female that had received the litter which was 9 days younger than her own stopped accepting extra-familial young when the 'adopted' litter was only about 30 days old, whereas, the female that received the older litter continued to accept extra-familial young (under 40 days old) until her 'adopted' litter was nearly 50 days old. After 40 days post partum both females, when presented with their own young, attacked them as if they were extra-familial.

Influence of acquired odour. In three trials with babies older than 40 days $(42,51,52$ days), one baby was placed for a few minutes into the nest of another squirrel (empty at the time) and two were handled with the same glove with which extra-familial young had been handled previously. In all three trials, the females rushed at their own babies when they were returned to the cages and began to attack, but stopped short of causing injury. In numerous other instances when babies (older than $\mathbf{4 0}$ days) were taken from and returned to their nests, but handled with clean gloves or with bare, washed hands the females were not aggressive toward them.

Twice, when gloves which had been used in handling extra-familial litters were placed in cages of two females that had litters exceeding 40 days in age, the females rushed at the glove and in one instance the glove was bitten. These females were not aggressive toward clean gloves placed in their cages.

Response towards nuts. Two females were tested which had litters born in September (beginning of intensive food storing); during these experiments (performed on 29 and 30 September) each baby was presented together with a hickory nut. Of seventy trials, the females took the hickory nut sixty-six times and the baby four times. Unlike normal storing behaviour, the females took the nuts to the nest and covered them with nesting material. After a few retrievals of nuts the females no longer placed them in the nest but stored them in the corners of the cage. Subsequent to the presentation of hickory nuts, young were again presented 
and in some instances the females 'stored' them, even to the extent of 'pounding' (Muul 1968) the babies into place while the latter emitted sounds of distress. The 'pounding' behaviour in food storing ensures that items such as nuts and acorns are firmly lodged between branches or in other crevices and involves quite a lot of physical force (enough to evoke distress cries from the young).

Strength of the retrieving response. Although no quantification was attempted of the strength of the retrieving response in the females as their litters became older, it was evident that those with young babies were quicker to retrieve than those with older babies and that the response of each female became slower as their litters became older.

\section{Discussion}

Owing to the serendipitous nature of these observations there are aspects that seem incomplete in hindsight; their significance emerged only after the loss of opportunity to repeat some of the experiments. Yet several aspects of retrieving behaviour of flying squirrels appear clear from these observations.

The retrieving response is strong. This would be expected because of the probability that young may fall from the arboreal nests or that the nests may be destroyed in a windstorm. Nests in the areas studied were usually built in woodpecker holes, often in trees so rotted that they were barely strong enough to stand and could be pushed over easily.

Experimental evidence indicates that until about 40 days post partum the retrieving response appears to prevail over the female's potential ability to recognize extra-familial individuals less than about 40 days old. Extrafamilial individuals older than 40 days do not dispose the female to retrieve and instead elicit aggressive behaviour. At 40 days, the young are fully furred, take solid food (although they are still nursing), and are quite coordinated in their movements (Table I). The females were less prone to retrieve their own young when they reached this age and preferred to retrieve younger individuals in the choice experiments.

Thus, there appear to be two conflicting and mutually exclusive behavioural responses elicited by the babies. Toward extra-familial individuals under 40 days of age retrieving response (maternal behaviour) predominates over the aggressive response (territorial behaviour). Extra-familial individuals over 40 days old evoke only the aggressive response, as do aḍulțs,
Moreover, after about 40 days post partum the behaviour of the females appears to change independently of the development of the young; the females were aggressive toward extra-familial individuals of all ages including those less than 40 days old. The experiment involving the exchange of litters between two females further illustrates this point. The change in the behaviour of the females occurred after 40 days post partum, apparently uninfluenced by the development of the litters in their charge which were 9 days behind and 9 days ahead of the temporal pattern of behavioural changes in the respective females.

It is reasonable to propose that this change in behaviour of the female may have an hormonal basis. Although lactation commonly continues up to and sometimes beyond 60 days post partum, females have been observed to be pregnant during the latter phases of the post partum care period (Hibbard 1935). Post partum ovulation is associated with hormonal changes even if no second pregnancy occurs. Studies of hormonal effects might be fruitful because ovulation in the flying squirrel occurs only a few times each year (Sollberger 1943), unlike in most small mammals in which retrieving has been studied.

While the retrieving response is partly dependent on visual stimuli, especially prior to 40 days post partum, the ability to distinguish strangers and associated aggressive behaviour appears to depend largely on odour. The importance of visual stimuli was demonstrated when the females retrieved younger babies more frequently than older ones (when the age difference was 18 to 19 days). The younger babies apparently provided a stronger visual stimulus for retrieving than the older ones. Odour in this case apparently had little effect since approximately half of these younger babies retrieved were extra-familial. When the age difference was less ( 2 to 9 days) there was no marked difference in the frequency at which younger and older babies were taken. Thus, odour or other 'alien' stimuli of extra-familial babies under 40 days of age apparently had little effect on the female's behaviour until 40 days post partum. However, after the 'transition' period ( 40 days post partum) the role of odour appeared paramount. This was illustrated by the reactions of the females toward their own young that were temporarily placed in another squirrel's nest, toward their own young that had been handled with gloves previously useed in handling other squirrels, 
ANIMAL BEHAVIOUR, 18,1

and toward gloves used in handling other squirrels. An obvious difference between the intrafamilial young and the gloves toward which the females responded aggressively and those toward which they did not was the odour of extra-familial squirrels, which the former apparently picked up while they were in the other squirrels nest or from the gloves that were previously used in handling extra-familial squirrels. After $\mathbf{4 0}$ days post partum, the two females whose litters were exchanged prior to the 'transition' period also reacted aggressively toward their own young apparently because of the odour of the nest in which they had been living. It was evident that little or no odour was retained by the young from their mother's nest prior to the exchange and their own odour (if they had any) with which their mothers might have been familiar was masked by the odour of the 'foster' mother.

This tempts one to speculate that the females respond aggressively (territorial behaviour) when stimulated by odour of other adults. Moreover, at about 40 days of age the level of the production of this 'adult odour' appears to reach a threshold, after which there appears to be a sufficient amount to elicit aggressive behaviour (territorial behaviour) in the female. However, until 40 days post partum, any 'adult odour' picked up secondarily by intra- or extra-familial babies does not elicit an aggressive response in the female because she is disposed to retrieve. Until the 'transition' period (40 days post partum) the retrieving response apparently takes precedence over aggressive behaviour.

Eibl-Eibesfeldt (1963) remarked on the similarity in the sequence of movements involved in nest building and young-retrieval in squirrels. In his experiments concerning young-retrieval, four out of forty-nine female squirrels attempted to 'store' their young in the food store-pile instead of taking them to the nest. During the present study females tested during the seasonal intensive storing period were easily induced to retrieve hickory nuts in place of babies. The female's initial response to the nuts was similar to that toward babies, i.e. the nuts were placed in the nest and nesting material was arranged over them. After such behaviour shifted to normal food storing (with nuts placed in the corners of the cage and 'pounded' into place) and the babies were presented again, the females sometimes 'stored' the babies instead of bringing them to the nest. Moreover, during the intensive food storing period, the females preferred hickory nuts to babies in retrieval experiments.

These results and the observations of EiblEibesfeldt suggest that food storing behaviour and retrieving behaviour are evolutionarily related. If one were permitted to speculate rather broadly, perhaps the former was derived from the latter since many mammals retrieve their young but fewer carry food and store it. Both retrieving and food storing are complex behaviour patterns which are influenced by many factors. Basically, however, the initial response in the retrieval of young or transport of food items is similar. The point of divergence occurs when the female is disposed to take the transported object either to the nest or to the store-pile. If the two behaviour patterns were unrelated the specific stimulus from each object, the baby or the nut, would act as a 'releaser' of a specific response. But, if one behaviour is a modification of another, one would expect a certain amount of 'cross-wiring' in the coordinating centres in the brain, unless, of course, there was natural selection against this and that the avoidance of confusion was paramount. In this particular case, however, the probability of females in nature confronting and being confused by situations with which they were presented experimentally is probably negligible. Thus, there appears to be preserved some evidence of relationship in the evolutionary development of these behaviour patterns.

Alternatively this phenomenon might be thought of as a displacement behaviour. But within the usual interpretation of displacement behaviour it would be difficult to explain why in some cases after the females had been induced to retrieve nuts and then shifted to normal food storing behaviour, they 'stored' the young subsequently presented to them instead of retrieving and placing them in the nest.

\section{Summary}

Experimental analysis and observational data on retrieving behaviour in female flying squirrels, Glaucomys volans, indicate that the retrieving drive is very strong, that females prior to 40 days post partum do not distinguish between their own young and those of other females (provided the babies are less than 40 days old), and that extra-familial young are usually attacked after 40 days post partum. Younger babies were retrieved by females more frequently than older ones (when the age difference was 18 to 19 days), regardless of whether they were intra- or extra-familial. Experimental evidence, 
although limited, suggests that odour is important in the female's ability to distinguish (1) between her own and extra-familial young over 40 days old, and (2) extra-familial young of any age after $\mathbf{4 0}$ days post partum. Females that had litters during the annual intensive food storing period retrieved nuts, when these were presented in lieu of babies, and placed them in their nests. Females sometimes 'stored' their babies when these were presented after a sequence of nut retrieving.

\section{Acknowledgments}

These observations were supplemental to a study supported by NSF grant (GB 482) to Professor W. H. Burt. I am grateful to Professor Burt for his interest and help throughout the study.

\section{R E F E R E N C E S}

Beach, F. A. \& Jaynes, J. (1956). Studies on maternal retrieving in rats: II. Effects of practice and previous parturitions. Am. Nat., 90(851), 103-109.
Eibl-Eibesfeldt, Von I. (1963). Angeborenes und Erworbenes im Verhalten einiger Sauger. Z. Tierpsychol., 20(6), 705-754.

Hart, F. M. \& King, J. A. (1966). Distress vocalizations of young in two subspecies of Peromyscus maniculatus. J. Mammal., 47, 287-293.

Hibbard, C. W. (1935). Breeding seasons of gray squirrels and flying squirrels. J. Mammal., 16, 325-326.

Muul, I. (1968). Behavioral and physiological influences on the distribution of the flying squirrel, Glaucomys volans. Misc. Publs Mus. Zool. Univ. Mich., 134, $1-66$.

Richards, M. R. (1968). Maternal behavior in rodents and lagomorphs. In Advances in Reproductive Physiology, Vol. II (ed. by McLaren), pp. 53-110. London: Lagos Press.

Sollberger, D. E. (1943). Notes on the life-history of the small eastern flying squirrel (Glaucomys volans volans). J. Mammal., 24, 163-173.

Stack, J. W. (1925). Courage shown by flying squirrel, Glaucomys volans. J. Mammal., 6(2), 128-129.

Zippelius, H. M. \& Schleidt, W. M. (1956). Ultraschallaute bei jungen Mausen. Nátúrwissenschaften 43, 508.

(Received 2 August 1968; revised 14 December 1968; MS. number: A730) 